\title{
Laparoscopic Splenectomy for Traumatic Splenic Injury after Screening Colonoscopy
}

\author{
Salim Abunnaja Lucian Panait J. Alexander Palesty \\ Shady Macaron
}

The Stanley Dudrick Department of Surgery, Saint Mary's Hospital, Waterbury, Conn., USA

\section{Key Words}

Colonoscopy · Splenic injury · Laparoscopic splenectomy

\begin{abstract}
Colonoscopy is a widespread diagnostic and therapeutic procedure. The most common complications include bleeding and perforation. Splenic rupture following colonoscopy is rarely encountered and is most likely secondary to traction on the splenocolic ligament. Exploratory laparotomy and splenectomy is the most commonly employed therapeutic intervention for this injury reported in the literature. We present the case of a patient with this potentially fatal complication who was treated successfully at our institution. To our knowledge it is the first report in the literature of laparoscopic splenectomy as a successful minimally invasive treatment of splenic rupture following colonoscopy. The patient was a 62 -year-old female who underwent screening colonoscopy with polypectomies at the cecum, descending colon and rectum. Immediately following the procedure she developed abdominal pain and had a syncopal episode. Clinical, laboratory and imaging findings were suggestive of hemoperitoneum and a ruptured spleen. A diagnostic laparoscopy was emergently performed and revealed a grade IV splenic laceration and hemoperitoneum. Laparoscopic splenectomy was completed safely and effectively. The patient's postoperative recovery was uneventful. We conclude that splenic rupture after colonoscopy is a rare but dangerous complication. A high index of suspicion is required to recognize it early. Awareness of this potential complication can lead to optimal patient outcome. Laparoscopic splenectomy may be a feasible treatment option.
\end{abstract}

\section{Introduction}

Colonoscopy is a very popular and well-tolerated diagnostic and therapeutic procedure. The most common complications of colonoscopy are perforation 
(0.34-2.14\%) and hemorrhage (1.8-2.5\%) [1]. Other unusual complications include pneumothorax, pneumoperitoneum, mesenteric tears, volvulus, hernia incarceration and retroperitoneal abscess [2]. Acute appendicitis after colonoscopy has also been reported but is very rare and seems to be due to luminal occlusion by a fecalith during the endoscopic maneuvers [3].

Splenic rupture is another extremely rare complication of a colonoscopy. The first case of splenic rupture from a colonoscopy was published in 1974 by Wherry and Zehner [4]. However, with the recent increase in the number of screening colonoscopies being performed, more cases of splenic rupture are being reported. Patients affected by this unusual complication display a female preponderance (F 75.4\%, M 24.6\%) [5] and a mean patient age of 63.0 years (range 29-90 years) [5]. They usually present within the first $24 \mathrm{~h}$ after colonoscopy [6-8], but many times the diagnosis is delayed for several days because mild symptoms are attributed to colonic insufflations $[2,4,7,9-11]$. CT scan is the imaging modality of choice $[12,13]$, determining the extent of splenic damage and demonstrating hemoperitoneum.

The majority of reported cases have been managed with emergent exploratory laparotomy and splenectomy. Few have been treated conservatively, and none have been managed by laparoscopic splenectomy. We report a 62 -year-old woman who developed a post-colonoscopy splenic injury that was diagnosed by CT scan and successfully managed with an emergent laparoscopic splenectomy.

\section{Case Report}

A 62-year-old female with no significant past medical or surgical history underwent a screening colonoscopy at a community teaching hospital. Her colonoscopy was conducted under light sedation and without difficulties. The exam showed smooth sessile polyps in the cecum, descending colon and the rectum, all of which were removed with snare polypectomy.

Prior to discharge from the endoscopy suite, the patient had a syncopal attack that was attributed initially to the effect of the sedation; however the patient simultaneously began to complain of vague abdominal pain. She was pale, anxious, hypotensive and tachycardic. Examination of her abdomen revealed diffuse rebound tenderness. A rectal examination revealed no gross ble eding. Initial laboratory tests included a white blood cell count of $11,800 / \mathrm{mm}^{3}$, a hemoglobin of $11.6 \mathrm{~g} / \mathrm{dl}$, a platelet count of $271,000 / \mathrm{mm}^{3}$ and a creatinine of $0.7 \mathrm{mg} / \mathrm{dl}$. An X-ray of the chest and abdomen revealed no evidence of air within the peritoneal cavity. Further evaluation with CT scan of the abdomen revealed a moderate-sized hemoperitoneum along with a ruptured spleen (fig. 1, fig. 2 ).

The patient responded appropriately to resuscitation with $2 \mathrm{l}$ of lactated Ringer's solution and $2 \mathrm{U}$ of packed red blood cells, but given the severity of the splenic injury splenectomy was considered appropriate. The laparoscopic approach was offered to the patient given her stable hemodynamic condition at that point (normal mental status, blood pressure and heart rate). After consenting for surgery she was taken to the operating room where she was placed in a right lateral decubitus position in preparation for laparoscopic splenectomy.

The initial diagnostic laparoscopy showed blood throughout the abdomen and a grade IV splenic injury with active bleeding from the splenic hilum. Laparoscopic splenectomy was successfully carried out after suctioning the hemoperitoneum and dividing the splenic artery and vein with a Ligasure device. The total operative time was $42 \mathrm{~min}$. The patient had an uneventful recovery and was discharged home on postoperative day 5. Based on the recommendations of the Centers for Disease Control and Prevention and of the Society of Surgery for the Alimentary Tract, she was given the pneumococcal polysaccharide vaccine PPV-23 (Pneumovax ${ }^{\circledR}$ ), Quadrivalent conjugated meningococcal vaccine and Haemophilus influenzae vaccine prior to discharge. 


\section{Discussion}

Wherry and Zehner [4] first reported this type of complication in 1974 when they documented one case of splenic trauma out of 247 colonoscopies. Since then many cases have been reported [3]. Although the exact reasons for development of a subcapsular or intraparenchymal hematoma after colonoscopy are not entirely clear, three mechanisms have been postulated. The first one is related to the sudden trauma caused when the endoscope traverses the splenic flexure [2]. The second one is related to the avulsion of the splenic capsule caused by excessive traction on the splenocolic ligament during the endoscopic examination and torque of the endoscope $[14,15]$ (fig. 3). A higher incidence of splenic rupture has also been reported in therapeutic colonoscopies were biopsies or polypectomies were performed [15]. The third theory implicates traction from the torque of the endoscope on adhesions between the spleen and the colon caused by previous surgical interventions or inflammatory processes [4]. This is unlikely in our case since our patient had no prior abdominal surgeries. Based on the second and third postulated mechanisms, positioning of the patient theoretically may play a role in preventing splenic injury during a colonoscopy. In the left lateral position, both the spleen and the splenic flexure fall to the left side, thereby any adhesions between them will be lax and the risk of splenic injury will be lower [10].

Clinical features such as abdominal pain, hypotension and tachycardia usually start within $24 \mathrm{~h}$ of the colonoscopy, but in some cases the symptoms can be delayed for several days $[2,4,7,9-11]$. The management of splenic injury following colonoscopy may be operative or nonoperative, similar to any other splenic trauma. In the literature, 9 patients were successfully treated conservatively with transfusions and close monitoring [16] and 2 patients had successful selective splenic artery embolization $[17,18]$. The rest of the reported cases were all managed operatively with exploratory laparotomy and splenectomy.

\section{Conclusion}

Splenic rupture after colonoscopy is a rare but dangerous complication, and a high index of suspicion is needed to recognize it early. To our knowledge, this is the first report of laparoscopic splenectomy employed in the treatment of a splenic rupture after colonoscopy. This case is instrumental in that it demonstrates that similar to any other splenic trauma, laparoscopic splenectomy may be a feasible treatment option; however, in lieu of an advanced laparoscopic skill set and/or adequate laparoscopic experience, the threshold to convert to an open splenectomy should be low. 


\begin{tabular}{r|l|l|l}
$\begin{array}{r}\text { Case Reports in } \\
\text { Gastroenterology }\end{array}$ & $\begin{array}{l}\text { Case Rep Gastroenterol 2012;6:624-628 } \\
\text { DOI: 10.1159/000343428 }\end{array}$ & $\begin{array}{l}\text { Published online: } \\
\text { September 28, 2012 }\end{array}$ & $\begin{array}{l}\text { @ 2012 S. Karger AG, Basel } \\
\text { ISSN 1662-0631 } \\
\text { www.karger.com/crg }\end{array}$ \\
\hline
\end{tabular}

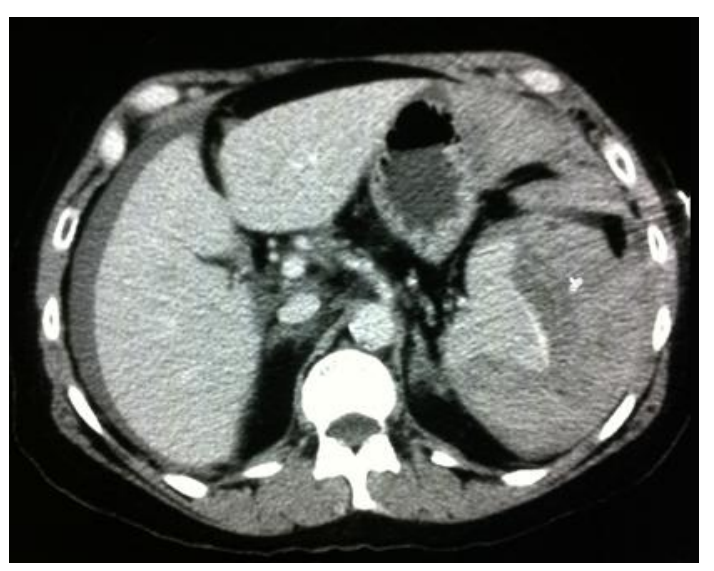

Fig. 1. Cross section CT scan of the abdomen revealing hemoperitoneum and a ruptured spleen.

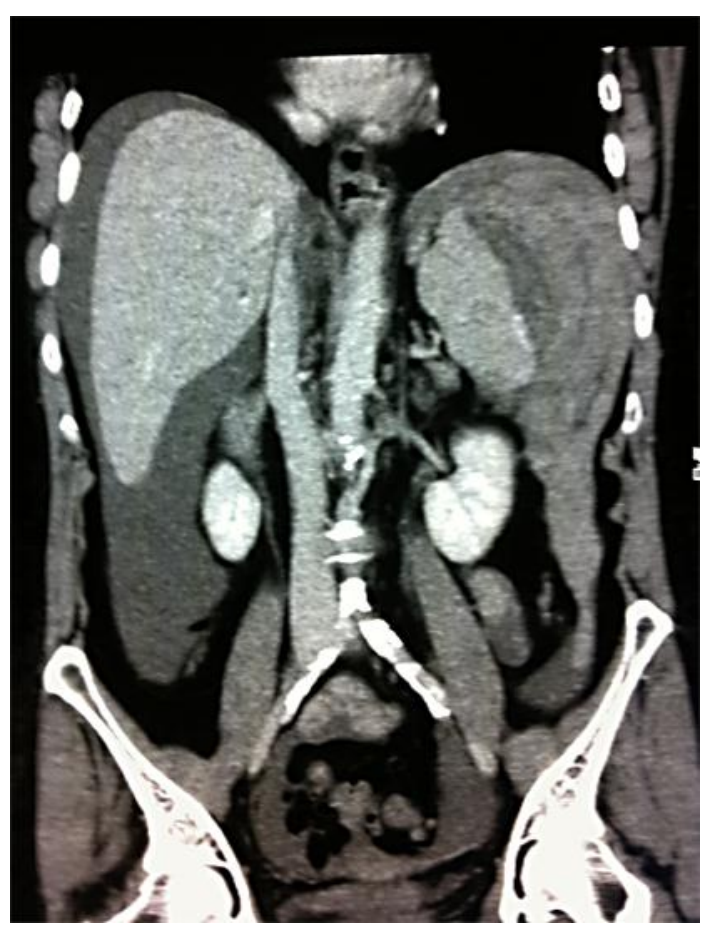

Fig. 2. Coronal section CT scan of the abdomen revealing hemoperitoneum and a ruptured spleen. 


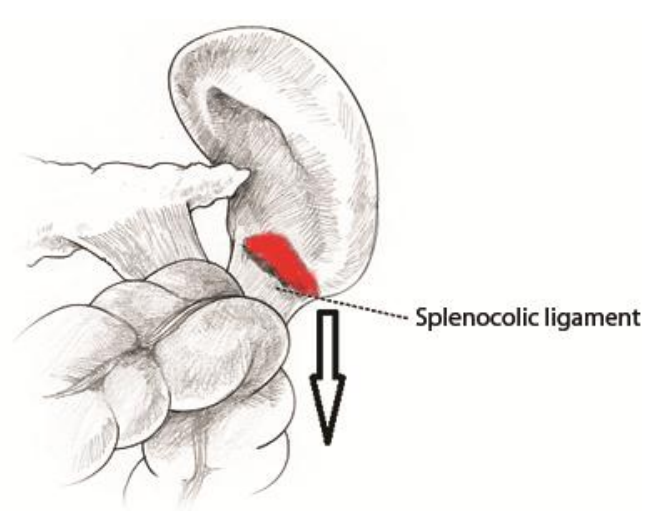

Fig. 3. Etiological mechanism: avulsion of the splenic capsule caus ed by excessive traction on the splenocolic ligament during the endoscopic examination and torque of the endoscope.

\section{References}

1 Castelli M: Splenic rupture: an unusual late complication of colonoscopy. CMAJ 1986;134:916-917.

-2 Olshaker JS, Deckleman C: Delayed presentation of splenic rupture after colonoscopy. J Emerg Med 1999;17:455-457.

3 Volchok J, Cohn M: Rare complications following colonoscopy: case reports of splenic rupture and appendicitis. JSLS 2006;10:114-116.

4 Wherry DC, Zehner H Jr: Colonoscopy-fiberoptic endoscopic approach to the colon and polypectomy. Med Ann Dist Columbia 1974;43:189-192.

5 Skipworth JR, Raptis DA, Rawal JS, et al: Splenic injury following colonoscopy - an underdiagnosed, but soon to increase, phenomenon? Ann R Coll Surg Engl 2009;91:W6-W11.

6 Lalor PF, Mann BD: Splenic rupture after colonoscopy. JSLS 2007;11:151-156.

$>7$ Ahmed A, Eller PM, Schiffman FJ: Splenic rupture: an unusual complication of colonoscopy. Am J Gastroenterol 1997;92:1201-1204.

8 Janes SE, Cowan IA, Dijkstra B: A life threatening complication after colonoscopy. BMJ 2005;330: 889-890.

9 Ellis WR, Harrison JM, Williams RS: Rupture of spleen at colonoscopy. Br Med J 1979;1:307-308.

$\checkmark 10$ Espinal EA, Hoak T, Porter JA, Slezak FA: Splenic rupture from colonoscopy. A report of two cases and review of the literature. Surg Endosc 1997;11:71-73.

11 Jaboury I: Splenic rupture after colonoscopy. Intern Med J 2004;34:652-653.

-12 Zenooz NA, Win T: Splenic rupture after diagnostic colonoscopy: a case report. Emerg Radiol 2006;12: 272-273.

13 Johnson C, Mader M, Edwards DM, Vesy T: Splenic rupture following colonoscopy: two cases with CT findings. Emerg Radiol 2006;13:47-49.

14 Viamonte M, Wulkan M, Irani H: Splenic trauma as a complication of colonoscopy. Surg Laparosc Endosc 1992;2:154-157.

15 Tsoraides SS, Gupta SK, Estes NC: Splenic rupture after colonoscopy: case report and literature review. J Trauma 2007;62:255-257.

16 Cappellani A, Di Vita M, Zanghi A, et al: Splenic rupture after colonoscopy: report of a case and review of literature. World J Emerg Surg 2008;3:8.

17 de Vries J, Ronnen HR, Oomen AP, Linskens RK: Splenic rupture following colonoscopy, a rare complication. Neth J Med 2009;67:230-233.

18 Stein DF, Myaing M, Guillaume C: Splenic rupture after colonoscopy treated by splenic artery embolization. Gastrointest Endosc 2002;55:946-948. 